\title{
Migration Gains to New Hampshire From Other U.S. States Are Growing, With the Largest Gains Among Young Adults
}

The net inflow of migrants to New Hampshire from other U.S. states was significantly greater between 2015 and 2019 than it was earlier in the decade, according to new Census Bureau data. Each year an average of 8,300 more people moved to New Hampshire than left it for other U.S. destinations between 2015 and 2019. In contrast, the net domestic migration gain was about 1,000 annually between 2010 and 2014, and just 100 annually during the Great Recession and its immediate aftermath. Migration gains were greatest among young adults (18 to 29), who had an average annual migration gain of 3,800 compared to no gain at all between 2010 and 2014. Among those in their 30s, the net annual migration gain more than doubled during the same period, while the net inflow of those 40 to 49 diminished. As more adults in their 20s and 30s migrated to New Hampshire, they brought their children as reflected in the migration gain among those under age 18. In contrast, among those age 50 and over, there was a minimal net migration gain each year compared to a small loss annually between 2010 and 2014. Modest migration from other countries at all ages supplemented the domestic migration gains analyzed here. These recent domestic and international migration gains provide additional human and social capital to a state challenged by an aging workforce and population.

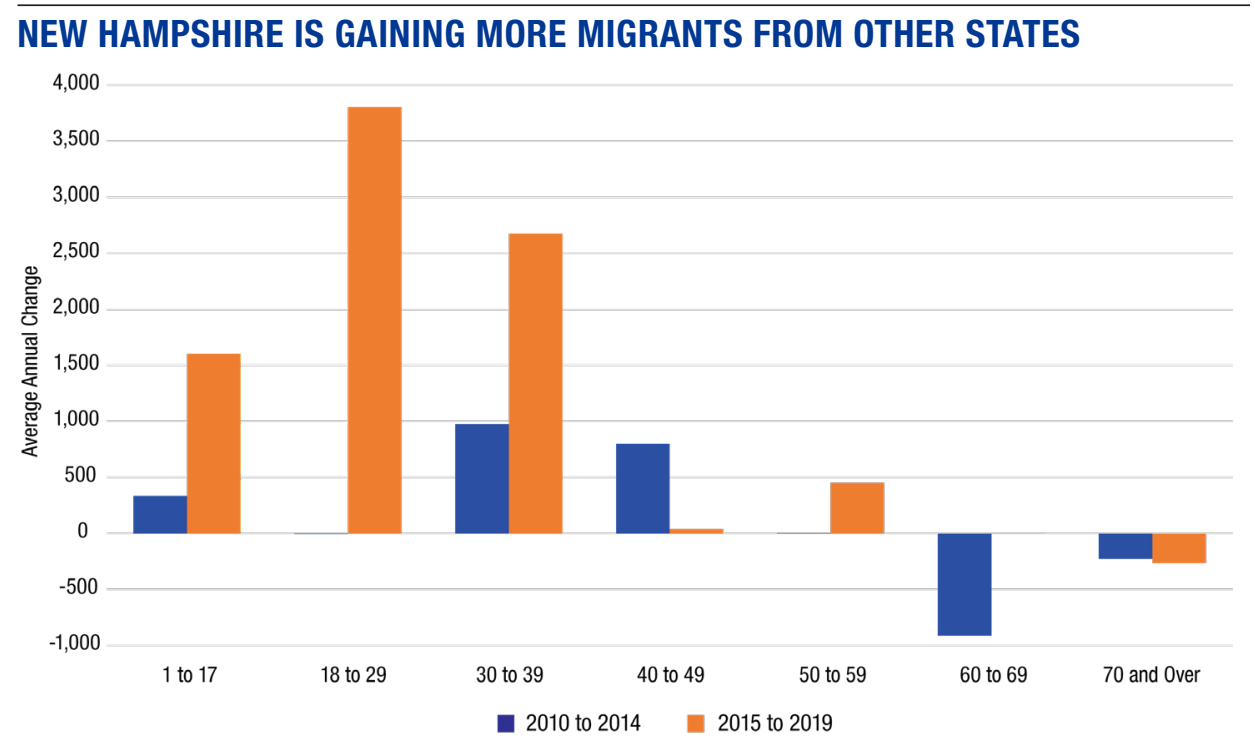

Analysis: K.M. Johnson, Carsey School, University of New Hampshire. Source: U.S. Census ACS, 2010-2014, 2015-2019. Note: This analysis uses sample estimates and should be interpreted with caution.

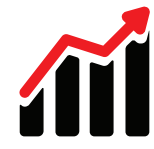

New Hampshire is now gaining significantly more migrants from other U.S. destinations than earlier in the decade. The largest gains are among young adults.

\section{See Related Publications at carsey.unh.edu}

-Why People Move to and Stay in New Hampshire (July 2020)

- New Hampshire Demographic Trends in an Era of Economic Turbulence (November 2019)

\footnotetext{
About the Author

Kenneth M. Johnson is senior demographer at the Carsey School of Public Policy, Class of 1940 professor of sociology at the University of New Hampshire, and an Andrew Carnegie Fellow. His research was supported by the New Hampshire Agricultural Experiment Station in support of Hatch Multi-State Regional Project W-4001 through joint funding of the National Institute of Food and Agriculture, U.S. Department of Agriculture, under award number 1013434, and the state of New Hampshire. The opinions are his and not those of the sponsoring organizations
} 